\section{Methods of Isolating Actinomycetes from the Soils of Menengai Crater in Kenya}

\section{Abstract}

This study was carried out to investigate the best method isolating actinomycetes from the soils of Menengai crater. Based on land terrain and differences in vegetation, the study area was divided into regions $A, B, C$ and $D$. Soil samples were collected from 8 sampling points from each region. The samples were separately mixed to form composite samples. To isolate actinomycetes, three isolation media such as starch casein (SC), Luria Bertani (M1) and starch nitrate (SN) agar were used. Prior to isolation, the soil samples were heat for $1 \mathrm{~h}$ at $121^{\circ} \mathrm{C}$. In serial dilution method, serial dilution upto $10^{-6}$ was carried out. On the other hand, in membrane filtration the pre-treated soil samples were sprinkled on the membrane filters previously placed on the isolation media and the membranes were removed after $4 \mathrm{~d}$ of incubation. Direct inoculation involved application of 2-3 mg of soil on the culture media. Characterization of the isolates was carried out by cultural, morphological and biochemical means. There was a significant difference in the number of actinomycetes isolated using the three media ( $F=7.252999 P=0.000897)$. The number of actinomycetes isolated using serial dilution, membrane filtration and direct inoculation were also significantly different $(F=8.683374 P=0.000237)$. Likewise, the number of actinomycetes isolated from region $A, B C$, and $D$ varied significantly ( $F=27.50 P=0.000)$.

Keywords: Actinomycetes; Crater; Isolation; Kenya; Menengai

\section{Paul Njenga $\mathbf{W}^{1}$, Mwaura FB ${ }^{1}$, Wagacha JM ${ }^{1}$ and Gathuru EM ${ }^{2}$}

1 University of Nairobi, School of Biological Sciences, P.O. Box, 30197-00100 Nairobi, Kenya

2 Egerton University, Department of Biological Sciences, P.O. Box, 536 Njoro, Kenya

Corresponding author: Paul Njenga W

\section{waithakanj@yahoo.com}

University of Nairobi, School of Biological Sciences, P.O. Box, 30197-00100 Nairobi, Kenya.

Tel: +254721104637

Citation: Njenga WP, Mwaura FB, Wagacha JM, et al. Methods of Isolating Actinomycetes from the Soils of Menengai Crater in Kenya. Arch Clin Microbiol. 2017, 8:3.

Received: May 19, 2017, Accepted: May 26, 2017, Published: June 03, 2017

\section{Introduction}

Actinomycetes are filamentous bacteria that show fungi like growth [1-5]. They are principally aerobic and wide spread in soils. Their DNA has a GC composition of $57-75 \%$. The major significance of actinomycetes lies in their ability to produce antibiotics [6-9]. Indeed, many of the currently known antibiotics such as streptomycin, gentamicin, rifamycin and erythromycin come from actinomycetes. Apart from the fore mentioned, actinomycetes also produce enzymes, vitamins and pigments that can be put to other uses [10-15].

In isolating actinomycetes, soil samples are collected from the study area [16-20]. To kill most of the Gram negative bacteria, the soil is dried on the bench inside the laboratory for a period of one week [17]. The soil is further held in a water bath at $50^{\circ} \mathrm{C}$ to further destroy other vegetative microorganisms [13].

Actionomycetes are then isolated using a number of techniques. One of the techniques that has gained popularity is weighing $1 \mathrm{~g}$ of the pre-treated soil [18]. The soil is placed in a test tube having
$9 \mathrm{ml}$ of distilled water. The mixture is agitated for $10 \mathrm{~min}$ at 200 rpm using an orbital shaker to make a stork solution [11]. Serial dilution is carried out by transferring $1 \mathrm{ml}$ of the stock solution to a second test tube with $9 \mathrm{ml}$ distilled water. This is done using other test tubes each having $9 \mathrm{ml}$ of distilled water until a dilution factor of $10^{-4}$ to $10^{-8}$ is achieved [13]. Plating is then carried out using a suitable media onto which an antibacterial and an antifungal agent has been added. The plates are incubated at $28^{\circ} \mathrm{C}$ for $5-25 \mathrm{~d}[7]$.

An alternative method is use of membrane filter technique [12]. In this method, a suitable agar medium such as starch casein is prepared by autoclaving at $121^{\circ} \mathrm{C}$ for $15 \mathrm{~min}$. After cooling of the medium to $45^{\circ} \mathrm{C}$, it is poured into petri dishes and allowed to settle [8]. Aseptically, membrane filters are placed at the centre of the plates. Soil is then sprinkled on the membrane filters [16]. Incubation is then carried out for roughly 4 days after which the membrane filters are removed [1]. The plates are further incubated until the actinomycetes become visible after which sub-culturing is done. This method is preferred due to 
its selectivity of actinomycetes [10]. It is based on the inability of other microbes to produce mycelia that can penetrate the membrane filter [6].

A third method which is not widely used in isolating actinomycetes is sprinkling of the pre-treated soil directly on the already prepared culture medium [3]. The plates are given time to allow contact between the soil particles and the medium. Incubation is then carried out at $28^{\circ} \mathrm{C}$ for $5-25 \mathrm{~d}$ [14].

This study aimed at establishing the best method of isolating actinomycetes from Menengai crater.

\section{Materials and Methods}

\section{Collection of soil samples}

Collection and processing of soil samples: The study area was sub-divided into four regions; $A, B, D$ and $D$. From each of the subdivisions, 8 two hundred grams sub-samples were collected from the top $5 \mathrm{~cm}$. In every region, the sub-samples were mixed to make a composite sample. The samples will separately be packed in polythene bags and carried to Egerton University, Department of Biological Sciences laboratories. The samples were separately air dried on the benches for one week. This was done to help reduce the population of gram negative bacteria [20]. Following this, the samples were separately sieved through $250 \mu \mathrm{m}$ pore size sieve (United Kingdom). Heat treatment was carried out by separately placing the samples ina hot air oven at $121^{\circ} \mathrm{C}$ for $1 \mathrm{~h}$ to prevent growth of other bacterial flora [1].

Preparation of culture media: Actinomycetes were cultured on starch casein agar (SCA) (starch $10 \mathrm{~g}, \mathrm{~K}_{2} \mathrm{HPO}_{4} 2 \mathrm{~g}, \mathrm{KNO}_{3} 2 \mathrm{~g}$, casein $0.3 \mathrm{~g}, \mathrm{MgSO}_{4} .7 \mathrm{H}_{2} \mathrm{O} 0.05 \mathrm{~g}, \mathrm{CaCO}_{3} 0.02 \mathrm{~g}$, $\mathrm{FeSO}_{4} .7 \mathrm{H}_{2} \mathrm{O} 0.01$ $\mathrm{g}$, agar $15 \mathrm{~g}$, filtered sea water $1000 \mathrm{ml}$ and $\mathrm{pH} 7.0 \pm 0.1$ ); Luria Bertani (M1) medium (starch $10 \mathrm{~g}$, Peptone $2.0 \mathrm{~g}$, yeast Extract $4.0 \mathrm{~g}$, Agar $18.0 \mathrm{~g}$, distilled water $1000 \mathrm{ml}, \mathrm{pH} ; 7.0 \pm 0.1$ ) and starch nitrate agar (soluble starch $20.0 \mathrm{~g}, \mathrm{~K}_{2} \mathrm{HPO}_{4} 1.0 \mathrm{~g}, \mathrm{KNO}_{3} 2.0$ g, $\mathrm{MgSO}_{4}$ 0.5G, $\mathrm{CaCO}_{3} 3.0 \mathrm{~g}, \mathrm{NaCl} 100 \mathrm{~g}, \mathrm{FeSO}_{4} 0.1 \mathrm{~g}, \mathrm{MnCl}_{2} 0.1 \mathrm{~g}$, $\mathrm{ZnSO}_{4} 0.1 \mathrm{~g}$, Distilled water $100 \mathrm{ml}, \mathrm{pH} 7.0 \pm 0.1$ ). The media were dissolved in distilled water as guided by the manufacturers prior to autoclaving at $121^{\circ} \mathrm{C}$ for $15 \mathrm{~min}$. The media were supplemented with $25 \mu \mathrm{g} \mathrm{ml}^{-1}$ nystatin do suppress growth of fungi and $10 \mu \mathrm{g}$ $\mathrm{ml}^{-1}$ nalidixic acid to minimize growth of Gram negative bacteria and some Gram positive bacteria.

\section{Methods of isolating actinomycetes}

Serial dilution technique: From each of the composite samples, $1 \mathrm{~g}$ of soil sample was separately added to a test tube containing $9 \mathrm{ml}$ distilled water and shaken vigorously at room temperature $\left(25 \pm 2^{\circ} \mathrm{C}\right)$, using an orbital shaker at $200 \mathrm{rpm}$ for $10 \mathrm{~min}$. The test tubes were considered as stock culture for the soil samples. Aseptically, $1 \mathrm{ml}$ aliquot from the stock solution was transferred to a test tube containing $9 \mathrm{ml}$ of sterile physiological saline and was mixed well. From these test tubes, $1 \mathrm{ml}$ of aliquot was again transferred and mixed with another $9 \mathrm{ml}$ of distilled water to make $10^{-2}$ dilution factor. Similarly, dilutions up to $10^{-6}$ were made using serial dilution technique for all soil samples [19].

After serial dilution, $0.1 \mathrm{ml}$ of each sample was separately plated using pour plate technique. The plates were incubated at $28^{\circ} \mathrm{C}$, and observed from $5^{\text {th }}$ day onwards for 25 days. After incubation, actinomycete isolates were distinguished from other microbial colonies by characteristics such as tough, leathery colonies which are partially submerged into the agar [21]. Colonies with suspected actinomycetes morphology were be sub-cultured on yeast extract malt extract agar medium and incubated at $28^{\circ} \mathrm{C}$ for 5 to 25 days. The pure cultures were maintained in slant culture on yeast extract malt extract agar (ISP2) as well as in glycerol broth at $4^{\circ} \mathrm{C}$ for further studies [14].

Membrane filter technique: On the previously prepared media, membrane filters were aseptically placed [3]. A soil sample (2-3 $\mathrm{mg}$ ) was sprinkled on the membrane filters of $0.45 \mu \mathrm{m}$ pore size (Figure 1). Incubation was carried out at $28^{\circ} \mathrm{C}$ for 4 days after which the membrane filters were removed. The plates were re-incubated for 2-3 weeks. Actinomycete colonies appearing on the plates were sub-cultured on M1 slants. For long-term preservation, the isolate was stored at $-4^{\circ} \mathrm{C}$ in $50 \%$ glycerol $(\mathrm{v} / \mathrm{v})$.

Direct inoculation technique: Soil samples (2-3 mg) were directly sprinkled on the culture medium in petri dishes (Figure 2) [2]. Time was taken to allow contact between the soil particles and culture media before incubation. Incubation was carried out at $28^{\circ} \mathrm{C}$ for $5-25$ days. Colonies showing typical actinomycetes characteristics were sub-cultured on yeast extract, malt extract agar. Pure cultures were preserved in $\mathrm{M} 1$ slant and $50 \%$ glycerol broth at $-4^{\circ} \mathrm{C}$ awaiting further processing.

\section{Characterization of the Isolates}

\section{Morphological characterization of actinomycetes}

Slide culture technique was used to study the morphological characteristics of the actinomycetes isolates. The isolates were

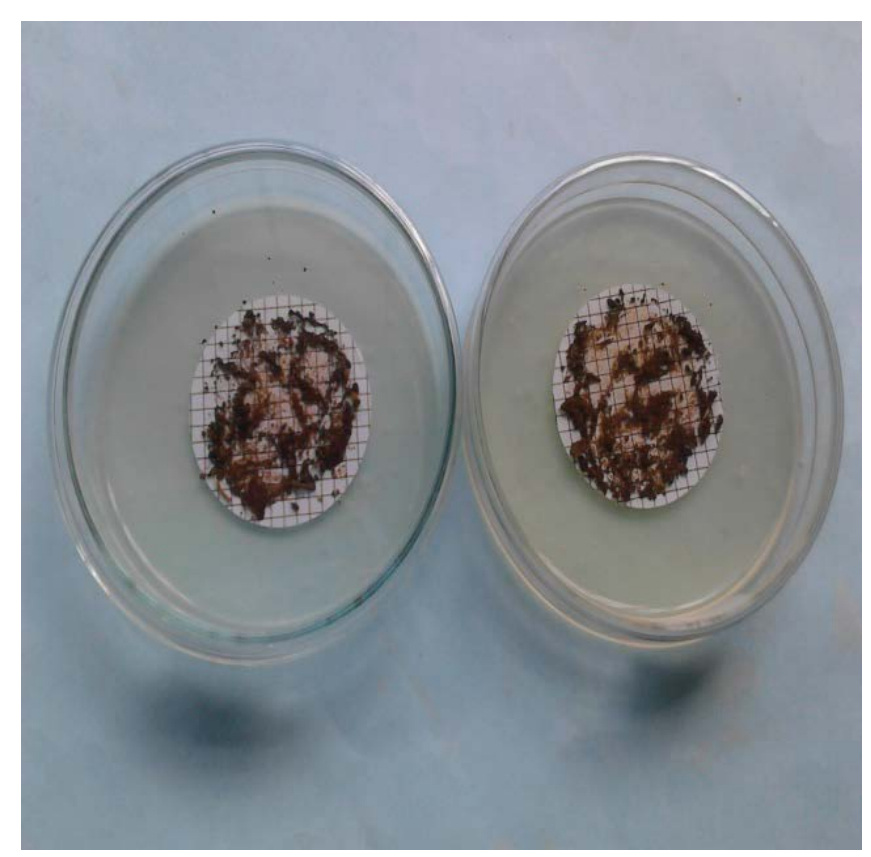

Figure 1 Membrane filters placed in M1 agar. 


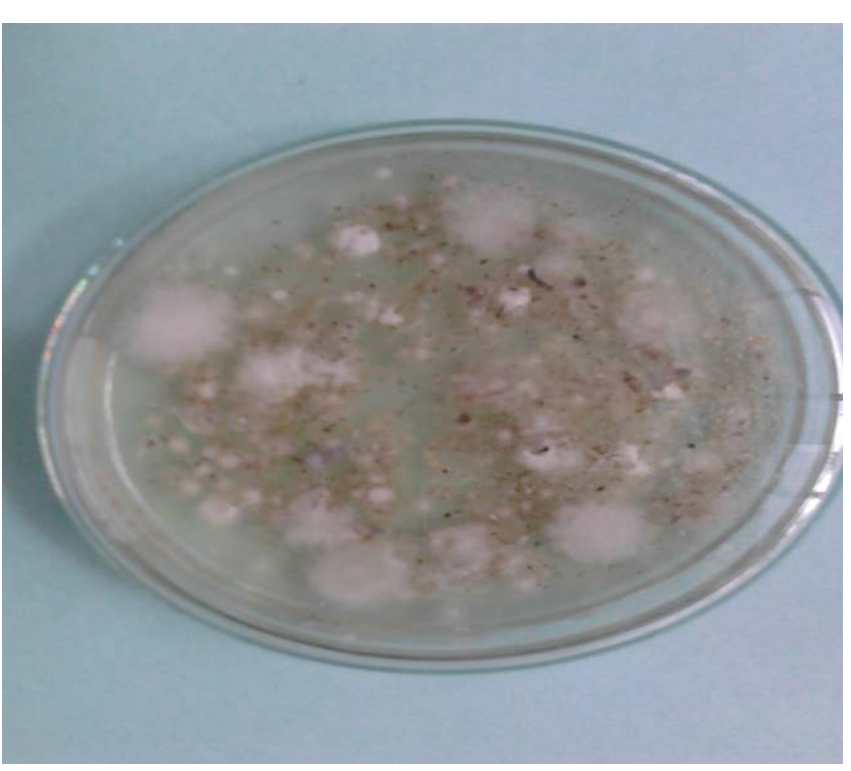

Figure 2 Soil samples on M1 media after direct inoculation with soil.

inoculated into M1 medium by streaking on the slide. Incubation of the slide was done at $37^{\circ} \mathrm{C}$ for $7 \mathrm{~d}$. Staining with methyleneblue was done followed by observation of the slides under the microscope after staining with methylene blue stain [21].

\section{Biochemical characterization of actinomycetes}

Gram's staining: Crystal violet, gram's iodine, 95\% ethyl alcohol and safranin were used in Gram staining. Aseptically, the isolated Actinomycetes were separately placed on glass slides using a wire loop. Crystal violet was added on the slides and allowed to stand for $1 \mathrm{~min}$. The excess stain was drained off using running tap water. Following this, Gram's iodine was added and the preparation allowed to stand for another $1 \mathrm{~min}$. The excess Gram's iodine was removed using tap water. Ethyl alcohol was added dropwise and later washed with running water. Safranin was added as a counter stain for $45 \mathrm{~s}$ before observation of the culture under the microscope [15].

Use of API strips: Large volumes of the isolated actinomycetes were inoculated into $0.85 \% \mathrm{Nacl}$. To standardize the inocula, McFarland units were used. The inocula were placed in the wells of API strips. The strips were incubated at $30^{\circ} \mathrm{C}$ and observed from the $5^{\text {th }} \mathrm{d}$ for up to 14 days [4].

Carbon source utilization: The ability of the isolates to utilize D-Glucose, D-Xylose, L-Arabinose, D-Fructose, D-Galactose, Raffinose, D-Mannitol, sucrose, maltose, lactose and cellulose were tested. The isolates were mixed $(1 \% \mathrm{w} / \mathrm{v})$ with the basal medium followed by incubation at $30^{\circ} \mathrm{C}$ for $7 \mathrm{~d}$ [15].

\section{Data Analysis}

The data obtained was analyzed using Statistical package for social sciences (SSPS) version 17.0 software. The means of actinomycetes isolated using serial dilution, membrane filtration and direct inoculation, means showing number of actinomycetes isolated from region $A, B C$, and means of actinomycetes from region $A, B, C$ and $D$ were compared using the three media were compared using ANOVA.

\section{Results}

\section{Number of actinomycetes isolated from Menengai crater}

The enumeration of actinomycetes from Menengai crater was carried out with the objective of determining their number in the soil samples. Among the actinomycetes isolated using serial dilution technique in region $\mathrm{A}$, the isolates varied from $2 \pm 3 \times 10^{8}$ to $9 \pm 2 \times 10^{3}$ in SC, M1 $\left(5 \pm 2 \times 10^{8}-14 \pm 3 \times 10^{3}\right)$ and SN $(4 \pm 3 \times$ $10^{8}-14 \pm 2 \times 10^{3}$ ) (Table 1 ). In region $B$, the variations were Sc (15 $\left.\pm 2 \times 10^{8}-25 \pm 3 \times 10^{3}\right), \mathrm{M} 1\left(20 \pm 3 \times 10^{8}-30 \pm 2 \times 10^{3}\right)$ and SN $(14 \pm$ $2 \times 10^{8}-27 \pm 3 \times 10^{3}$ ). The isolates from region $\mathrm{C}$ ranged from (16 $\left.\pm 2 \times 10^{8}-24 \pm 2 \times 10^{3}\right)$ in SC, M1 $\left(20 \pm 2 \times 10^{8}-31 \pm 3 \times 10^{3}\right)$ and SN $\left(17 \pm 3 \times 10^{8}-28 \pm 2 \times 10^{3}\right)$. In addition, Actinomycetes ranges in region D were SC $\left(5 \pm 2 \times 10^{8}-9 \pm 2 \times 10^{3}\right), \mathrm{M} 1\left(7 \pm 2 \times 10^{8}-15 \pm\right.$ $\left.3 \times 10^{3}\right)$ and SN $\left(4 \pm 3 \times 10^{8}-13 \pm 3 \times 10^{3}\right)$.

The actinomycetes isolated using membrane filtration method from region $A$ varied from $2 \pm 3 \times 10^{8}$ to $5 \pm 2 \times 10^{3}$ in SC, M1 ( 1 $\left.\pm 3 \times 10^{8}-11 \pm 3 \times 10^{3}\right)$ and SN $\left(1 \pm 3 \times 10^{8}-10 \pm 2 \times 10^{3}\right)$. In region $\mathrm{B}$, the ranges were SC $\left(11 \pm 2 \times 10^{8}-22 \pm 3 \times 10^{3}\right), \mathrm{M} 1(20 \pm 3 \times$ $\left.10^{8}-25 \pm 2 \times 10^{3}\right)$, SN $\left(12 \pm 2 \times 10^{8}-23 \pm 3 \times 10^{3}\right)$. Additionally the variations in region C were CS $\left(13 \pm 2 \times 10^{8}-21 \pm 2 \times 10^{3}\right), \mathrm{M} 1(17$ $\left.\pm 2 \times 10^{8}-28 \pm 3 \times 10^{3}\right)$, SN $\left(13 \pm 3 \times 10^{8}-25 \pm 2 \times 10^{3}\right)$. Moreover, in region $D$ actinomycetes isolates ranges were SC $\left(2 \pm 2 \times 10^{8}-6 \pm\right.$ $\left.2 \times 10^{3}\right), \mathrm{M} 1\left(4 \pm 2 \times 10^{8}-12 \pm 3 \times 10^{3}\right)$, SN $\left(1 \pm 3 \times 10^{8}-10 \pm 3 \times 10^{3}\right)$.

However, the actinomycetes isolated using the direct inoculation method varied in SC $\left(5 \pm 3 \times 10^{8}-13 \pm 2 \times 10^{3}, \mathrm{M} 1\left(8 \pm 3 \times 10^{8}-18 \pm\right.\right.$ $\left.3 \times 10^{3}\right)$ and $\mathrm{SN}\left(6 \pm 3 \times 10^{8}-17 \pm 2 \times 10^{3}\right)$. In region $\mathrm{B}$, the ranges were SC $\left(18 \pm 2 \times 10^{8}-29 \pm 3 \times 10^{3}\right)$, M1 $\left(22 \pm 3 \times 10^{8}-31 \pm 2 \times 10^{3}\right)$, SN $\left(16 \pm 2 \times 10^{8}-30 \pm 3 \times 10^{3}\right)$. The variations in region $\mathrm{C}$ were CS $\left(18 \pm 2 \times 10^{8}-29 \pm 2 \times 10^{3}\right), \mathrm{M} 1\left(21 \pm 2 \times 10^{8}-31 \pm 3 \times 10^{3}\right)$, SN $(20 \pm$ $\left.3 \times 10^{8}-30 \pm 2 \times 10^{3}\right)$. In addition, the ranges of actinomycetes in region D were SC $\left(5 \pm 2 \times 10^{8}-13 \pm 2 \times 10^{3}\right), M 1\left(11 \pm 2 \times 10^{8}-19 \pm\right.$ $\left.3 \times 10^{3}\right)$, SN $\left(6 \pm 3 \times 10^{8}-17 \pm 3 \times 10^{3}\right)$.

There was a significant difference in the number of actinomycetes isolated using the three media ( $F=7.252999 \quad \mathrm{P}=0.000897)$. The number of actinomycetes isolated using serial dilution, membrane filtration and direct inoculation were also significantly different $(F=8.683374 \quad P=0.000237)$. Likewise, the number of actinomycetes isolated from region $A, B$, and $D$ varied significantly $(F=27.50 \mathrm{P}=0.000)$.

\section{Morphological characteristics of actinomycetes isolated from Menengai crater}

Morphological characterization of the isolates was meant to determine the diversity on the isolates in the study area. Among the actinomycetes isolated using serial dilution technique, PAN 1-20 exhibited green aerial mycelium with yellow substrate mycelium (Table 2). The isolates neither produced diffusible pigments nor melanin pigments. They had a flat elevation and a rough surface. PAN 35-50 produced a dark grey surface mycelium 
Table 1: Number of actinomycetes isolated from soils of Menengai crater.

\begin{tabular}{|c|c|c|c|c|c|c|c|c|c|c|c|c|c|}
\hline \multirow{3}{*}{$\begin{array}{l}\text { Isolation } \\
\text { method }\end{array}$} & \multirow[t]{3}{*}{ DF } & \multicolumn{12}{|c|}{ Number of actinomycetes } \\
\hline & & \multicolumn{3}{|c|}{ Region A } & \multicolumn{3}{|c|}{ Region B } & \multicolumn{3}{|c|}{ Region C } & & \multicolumn{2}{|c|}{ Region D } \\
\hline & & SC & M1 & SN & SC & M1 & SN & SC & M1 & SN & SC & M1 & SN \\
\hline \multirow{6}{*}{$\begin{array}{c}\text { Serial } \\
\text { dilution }\end{array}$} & 3-Oct & $9 \pm 2$ & $14 \pm 3$ & $14 \pm 2$ & $25 \pm 3$ & $30 \pm 2$ & $27 \pm 3$ & $24 \pm 2$ & $31 \pm 3$ & $28 \pm 2$ & $9 \pm 2$ & $15 \pm 3$ & $13 \pm 3$ \\
\hline & 4-Oct & $6 \pm 2$ & $12 \pm 2$ & $10 \pm 2$ & $21 \pm 3$ & $30 \pm 2$ & $24 \pm 3$ & $22 \pm 2$ & $31 \pm 2$ & $25 \pm 2$ & $7 \pm 3$ & $11 \pm 3$ & $10 \pm 3$ \\
\hline & 5-Oct & $4 \pm 3$ & $10 \pm 2$ & $7 \pm 2$ & $19 \pm 2$ & $28 \pm 3$ & $21 \pm 3$ & $22 \pm 2$ & $30 \pm 3$ & $22 \pm 3$ & $5 \pm 2$ & $10 \pm 3$ & $11 \pm 2$ \\
\hline & 6-Oct & $3 \pm 2$ & $8 \pm 3$ & $8 \pm 3$ & $18 \pm 2$ & $26 \pm 2$ & $18 \pm 3$ & $17 \pm 3$ & $24 \pm 2$ & $21 \pm 3$ & $6 \pm 2$ & $10 \pm 2$ & $5 \pm 2$ \\
\hline & 7-Oct & $3 \pm 3$ & $7 \pm 2$ & $5 \pm 2$ & $15 \pm 3$ & $27 \pm 3$ & $15 \pm 2$ & $18 \pm 3$ & $22 \pm 2$ & $19 \pm 2$ & $5 \pm 2$ & $9 \pm 2$ & $3 \pm 2$ \\
\hline & 8-Oct & $2 \pm 3$ & $5 \pm 3$ & $4 \pm 3$ & $15 \pm 2$ & $20 \pm 3$ & $14 \pm 2$ & $16 \pm 2$ & $20 \pm 2$ & $17 \pm 3$ & $5 \pm 2$ & $7 \pm 2$ & $4 \pm 3$ \\
\hline \multirow{6}{*}{$\begin{array}{l}\text { Membrane } \\
\text { filtration }\end{array}$} & 3-Oct & $5 \pm 2$ & $11 \pm 3$ & $10 \pm 2$ & $22 \pm 3$ & $25 \pm 2$ & $23 \pm 3$ & $21 \pm 2$ & $28 \pm 3$ & $25 \pm 2$ & $6 \pm 2$ & $12 \pm 3$ & $10 \pm 3$ \\
\hline & 4-Oct & $3 \pm 2$ & $9 \pm 2$ & $7 \pm 2$ & $18 \pm 3$ & $23 \pm 2$ & $21 \pm 3$ & $18 \pm 2$ & $28 \pm 2$ & $22 \pm 2$ & $5 \pm 3$ & $8 \pm 3$ & $10 \pm 3$ \\
\hline & 5-Oct & $4 \pm 3$ & $8 \pm 2$ & $7 \pm 2$ & $15 \pm 2$ & $24 \pm 3$ & $17 \pm 3$ & $19 \pm 2$ & $27 \pm 3$ & $20 \pm 3$ & $5 \pm 2$ & $7 \pm 3$ & $6 \pm 2$ \\
\hline & 6-Oct & $2 \pm 2$ & $5 \pm 3$ & $6 \pm 3$ & $14 \pm 2$ & $23 \pm 2$ & $15 \pm 3$ & $14 \pm 3$ & $21 \pm 2$ & $17 \pm 3$ & $3 \pm 2$ & $7 \pm 2$ & $2 \pm 2$ \\
\hline & 7-Oct & $1 \pm 3$ & $4 \pm 2$ & $3 \pm 2$ & $12 \pm 3$ & $21 \pm 3$ & $12 \pm 2$ & $15 \pm 3$ & $19 \pm 2$ & $15 \pm 2$ & $3 \pm 2$ & $6 \pm 2$ & $1 \pm 2$ \\
\hline & 8-Oct & $2 \pm 3$ & $1 \pm 3$ & $1 \pm 3$ & $11 \pm 2$ & $20 \pm 3$ & $12 \pm 2$ & $13 \pm 2$ & $17 \pm 2$ & $13 \pm 3$ & $2 \pm 2$ & $4 \pm 2$ & $1 \pm 3$ \\
\hline \multirow{6}{*}{$\begin{array}{c}\text { Direct } \\
\text { inoculation }\end{array}$} & 3-Oct & $13 \pm 2$ & $18 \pm 3$ & $17 \pm 2$ & $29 \pm 3$ & $31 \pm 2$ & $30 \pm 3$ & $29 \pm 2$ & $31 \pm 3$ & $30 \pm 2$ & $13 \pm 2$ & $19 \pm 3$ & $17 \pm 3$ \\
\hline & 4-Oct & $10 \pm 2$ & $16 \pm 2$ & $15 \pm 2$ & $24 \pm 3$ & $30 \pm 2$ & $28 \pm 3$ & $26 \pm 2$ & $30 \pm 2$ & $28 \pm 2$ & $11 \pm 3$ & $15 \pm 3$ & $14 \pm 3$ \\
\hline & 5-Oct & $8 \pm 3$ & $13 \pm 2$ & $12 \pm 2$ & $22 \pm 2$ & $29 \pm 3$ & $25 \pm 3$ & $25 \pm 2$ & $29 \pm 3$ & $25 \pm 3$ & $8 \pm 2$ & $13 \pm 3$ & $13 \pm 2$ \\
\hline & 6-Oct & $7 \pm 2$ & $12 \pm 3$ & $11 \pm 3$ & $21 \pm 2$ & $26 \pm 2$ & $22 \pm 3$ & $21 \pm 3$ & $26 \pm 2$ & $23 \pm 3$ & $7 \pm 2$ & $12 \pm 2$ & $9 \pm 2$ \\
\hline & 7-Oct & $6 \pm 3$ & $10 \pm 2$ & $9 \pm 2$ & $19 \pm 3$ & $24 \pm 3$ & $18 \pm 2$ & $20 \pm 3$ & $23 \pm 2$ & $22 \pm 2$ & $7 \pm 2$ & $13 \pm 2$ & $7 \pm 2$ \\
\hline & 8-Oct & $5 \pm 3$ & $8 \pm 3$ & $6 \pm 3$ & $18 \pm 2$ & $22 \pm 3$ & $16 \pm 2$ & $18 \pm 2$ & $21 \pm 2$ & $20 \pm 3$ & $5 \pm 2$ & $11 \pm 2$ & $6 \pm 3$ \\
\hline
\end{tabular}

with a cream substrate mycelium. The isolates produced brown diffusible pigments only. Their surfaces were raised and rough. PAN81-100 had a violet colouration in both aerial and substrate mycelium. They produced violet diffusible pigments with no melanin pigments while their surfaces were raised and rough. PAN117-120 had dark brown aerial and brown subsurface mycelium with brown diffusible but no melanin pigments. The isolates had a rough surface that was rough. PAN134-138 had an orange surface mycelium with yellow subsurface mycelium. Their surface was raised and rough.

Membrane technique produced PAN 51-81 which were white on the surface bearing a cream substrate mycelium. The isolates produced neither diffusible nor melanin pigments. They had a raised elevation with a rough surface. PAN 106-116 had light brown with brown substrate mycelia. They produced brown diffusible pigments and had no melanin pigments. In PAN121126 , the aerial mycelia were blue while the substrate mycelia were black. The isolates did not produce any pigments. PAN131133 had black aerial and substrate mycelia with no production of pigments. The isolates had a raised surface that was rough.

In addition, among the actinomycetes produced through direct inoculating the soil in the culture medium, PAN 21-34 had grey aerial mycelium and cream substrate mycelium. The isolates didn't produce any pigments but the surface was flat and rough. Additionally, PAN 101-105 a purple surface bearing a black subsurface mycelium. The isolates gave brown diffusible pigments and had a flat surface that was rough. They had a surface that was raised and rough. The isolates PAN 127-130 produced dark blue aerial mycelium and blac substrate mycelium. Additionally, they produced brown diffusible and melanin pigments. Their surface was raised and rough. On the other hand, PAN 139-156 had peach surface mycelium with no pigments production but had a flat elevation that was rough.

\section{Biochemical characteristics of actinomycetes isolated from Menengai crater}

Biochemical characteristics of actinomycetes are used in their identification. All the isolates isolated using serial dilution, membrane filtration and direct inoculation, tested positive for Gram stain, catalase, oxidase, urea hydrolysis and gelatin liquefication (Table 3). However, they tested negative for deaminase and Indole production. PAN 101-105, PAN121-126 and PAN 139-152 were positive for beta-galactosidase while PAN 1-20, PAN 21-34, PAN 35-50, PAN 51-81, PAN 106-116, PAN 117-120, PAN 127-130, PAN 131-133 and PAN 134-138 were negative. PAN 1-20, PAN 51-81, PAN 117-120 and PAN 134-138 tested positive for lysine decarboxylase.

Conversely, PAN 21-34, PAN 35-50, PAN 81-100, PAN 101-105, PAN 106-116, PAN 121-126, PAN 127-130, PAN 131-133 and PAN 139-152 were negative for lysine decarboxylase. The isolates PAN 21-34, PAN 106-116, PAN 117-120, PAN 131-133, PAN 134138, PAN 134-138, PAN 139-152 were positive while PAN 1-20, PAN 35-50, PAN 51-81, PAN 81-100, PAN101-105, PAN 121-126, PAN 127-130 were negative for ornithine decarboxylase.

In addition, PAN 1-20, PAN 21-24, PAN81-100, PAN 101-105, PAN 105-116, PAN 117-120, PAN 121-126, PAN 127-130, PAN 131-133, PAN 134-138 and PAN 139-152 were positive for citrate utilization. Only PAN 35-50 and PAN 51-81 tested negative for citrate utilization. When tested for $\mathrm{H}_{2} \mathrm{~S}$ production, PAN 3550, PAN 51-81, PAN 117-120, PAN 121-126, PAN 131-133 were positive while PAN 1-20, PAN 21-34, PAN 81-100, PAN 101-105, PAN 106-116, PAN 127-130, PAN 134-138, PAN 139-152 tested negative. 
Table 2: Morphological and cultural characteristics of actinomycetes isolated from Menengai crater.

\begin{tabular}{|c|c|c|c|c|c|c|c|}
\hline Technique & Code & Aerial mycelium & $\begin{array}{l}\text { Substrate } \\
\text { mycelium }\end{array}$ & $\begin{array}{l}\text { Diffusible } \\
\text { pigments }\end{array}$ & $\begin{array}{l}\text { Melanin } \\
\text { pigments }\end{array}$ & Elevation & Surface \\
\hline \multirow[t]{5}{*}{ Serial dilution } & PAN 1-20 & Green & Yellow & - & - & flat & rough \\
\hline & PAN 35-50 & Dark grey & Cream & + & - & Raised & rough \\
\hline & PAN81-100 & Violet & Violet & + & - & raised & rough \\
\hline & PAN117-120 & Dark brown & Brown & + & - & flat & rough \\
\hline & PAN134-138 & Orange & Yellow & - & - & raised & smooth \\
\hline \multirow[t]{4}{*}{ Membrane filtration } & PAN 51-80 & White & Cream & - & - & raised & rough \\
\hline & PAN 106-116 & Light brown & Brown & + & - & flat & smooth \\
\hline & PAN121-126 & Blue & Black & - & - & raised & rough \\
\hline & PAN 131-133 & Black & Black & - & - & raised & rough \\
\hline \multirow[t]{4}{*}{ Direct inoculation } & PAN 21-34 & Grey & Cream & - & - & flat & rough \\
\hline & PAN 101-105 & Purple & Black & + & - & flat & rough \\
\hline & PAN127-130 & Dark Blue & Black & + & + & raised & rough \\
\hline & PAN 139-156 & Peach & Cream & - & - & flat & rough \\
\hline
\end{tabular}

Table 3: Biochemical characteristics of actinomycetes from Menengai Crater.

\begin{tabular}{|c|c|c|c|c|c|c|c|c|c|c|c|c|c|}
\hline \multirow[t]{3}{*}{ Test } & & \multicolumn{5}{|c|}{ Strain } \\
\hline & \multicolumn{5}{|c|}{ Serial dilution } & \multicolumn{4}{|c|}{ Membrane filtration } & \multicolumn{3}{|c|}{ Direct inoculation } & \multirow[b]{2}{*}{$\begin{array}{c}\text { PAN 139- } \\
156\end{array}$} \\
\hline & $\begin{array}{l}\text { PAN } \\
1-20\end{array}$ & $\begin{array}{c}\text { PAN 35- } \\
50\end{array}$ & $\begin{array}{l}\text { PAN } \\
81-100\end{array}$ & $\begin{array}{c}\text { PAN } \\
117-120\end{array}$ & $\begin{array}{c}\text { PAN } \\
134-138\end{array}$ & $\begin{array}{c}\text { PAN 51- } \\
81\end{array}$ & $\begin{array}{c}\text { PAN } \\
106-116\end{array}$ & $\begin{array}{c}\text { PAN } \\
121-126\end{array}$ & $\begin{array}{c}\text { PAN } \\
131-133\end{array}$ & $\begin{array}{c}\text { PAN 21- } \\
34\end{array}$ & $\begin{array}{c}\text { PAN 101- } \\
105\end{array}$ & $\begin{array}{c}\text { PAN } \\
127-130\end{array}$ & \\
\hline GS & + & + & + & + & + & + & + & + & + & + & + & + & + \\
\hline ONPG & - & - & - & - & - & - & - & + & - & - & + & - & + \\
\hline CAT & + & + & + & + & + & + & + & + & + & + & + & + & + \\
\hline GLU & + & + & + & + & + & + & + & + & + & + & + & + & + \\
\hline LDC & + & - & - & + & + & + & - & - & - & - & - & - & - \\
\hline ODC & - & - & - & + & + & - & + & - & + & + & - & - & + \\
\hline $\mathrm{CIT}$ & + & - & + & + & + & - & + & + & + & + & + & + & + \\
\hline $\mathrm{H}_{2} \mathrm{~S}$ & - & + & - & + & - & + & - & + & + & - & - & - & - \\
\hline URE & + & + & + & + & + & + & + & + & + & + & + & + & + \\
\hline TDA & - & - & - & - & - & - & - & - & - & - & - & - & - \\
\hline IND & - & - & - & - & - & - & - & - & - & - & - & - & - \\
\hline $\mathrm{GL}$ & + & + & + & + & + & + & + & + & + & + & + & + & + \\
\hline
\end{tabular}

GS: Gram Stain; ONPG; Beta-Galactosidase; CAT: Catalase Test; GLU: Oxidase; LDC: Lysine Decarboxylase; ODC: Ornithine Decarboxylase; CIT: Citrate Utilization; $\mathrm{H}_{2} \mathrm{~S}$ : Hydrogen Sulphide Production; URE: Urea Hydrolysis; TDA: Deaminase; IND: Indole Production; GL: Gelatin Liquefication.

\section{Carbon source utilization of actinomycetes isolated from Menengai crater}

In addition to biochemical characteristics, main carbon source utilization by actinomycetes are used in identification of actinomycetes. The isolates utelized D-glucose, D-galactose, sucrose, D-fructose and L-arabinose. However, all of them could not utilize cellulose, D-mannitol, salicin, raffinose and mesoinositol (Table 4). In addition, all the isolates apart from PAN 3550 could utilize sucrose. PAN 21-34, PAN 51-80, PAN 81-100, PAN 101-105, PAN 121-126, PAN 127-130, PAN 131-133, PAN 134-138, PAN 139-152 were positive while PAN1-20, PAN35-50, PAN106116, PAN117-120 were negative for lactose utilization. All the isolates utilized maltose apart from PAN 35-50 and PAN51-80.

\section{Discussion}

The number of actinomycetes isolated from Menengai crater using serial dilution, membrane filtration and direct inoculation are presented in (Table 1). Actinomycetes recovered from the soil using direct inoculation technique were higher than those obtained using serial dilution and membrane filtration method. This agreed with a previous study by Masoumeh et al. [9]. The probable reason for the observed results could be in the case of serial dilution, the dilutions reduce the number of actinomycetes. On the other hand membrane filtration sometimes interferes with the integrity of the cellular structure of the growing actinomycetes. As a result, after removal of the membrane structure, the remaining mycelia that had penetrated the membrane fail to grow [3]. The colonial morphology of the isolated actinomycetes exhibited characteristics of actinomycetes. A study carried out in Malaysia confirms these results [14]. However, a study carried out elsewhere slightly disagreed with the result of the current study [4]. The probable reason could be differences in the physichochemical characteristics of the soil from which the actinomycetes were growing [20]. The biochemical characteristics of the actinomycetes obtained in this study attest to the fact that the isolates were indeed actinomycetes. The results concurred with a study carried out formally by Pooja et al. [14] in the 
Table 4: Carbon source utilization of actinomycetes isolated from Menengai crater.

\begin{tabular}{|c|c|c|c|c|c|c|c|c|c|c|c|c|c|}
\hline & PAN 1-20 & $\begin{array}{c}\text { PAN 35- } \\
50\end{array}$ & $\begin{array}{c}\text { PAN } \\
81-100\end{array}$ & $\begin{array}{c}\text { PAN } \\
117-120\end{array}$ & $\begin{array}{c}\text { PAN } \\
134-138\end{array}$ & $\begin{array}{c}\text { PAN 51- } \\
80\end{array}$ & $\begin{array}{c}\text { PAN } \\
106-116\end{array}$ & $\begin{array}{c}\text { PAN } \\
121-126\end{array}$ & $\begin{array}{c}\text { PAN } \\
131-133\end{array}$ & $\begin{array}{c}\text { PAN 21- } \\
34\end{array}$ & $\begin{array}{c}\text { PAN 101- } \\
105\end{array}$ & $\begin{array}{c}\text { PAN } \\
127-130\end{array}$ & $\begin{array}{c}\text { PAN 139- } \\
156\end{array}$ \\
\hline DG & + & + & + & + & + & + & + & + & + & + & + & + & + \\
\hline DGal & + & + & + & + & + & + & + & + & + & + & + & + & + \\
\hline Cellulose & - & - & - & - & - & - & - & - & - & - & - & - & - \\
\hline Su & + & - & + & + & + & + & + & + & + & + & + & + & + \\
\hline DM & - & - & - & - & - & - & - & - & - & - & - & - & - \\
\hline Lactose & - & - & + & - & + & + & - & + & + & + & + & + & + \\
\hline Mal & + & - & + & + & + & - & + & + & + & + & + & + & + \\
\hline Salicin & - & - & - & - & - & - & - & - & - & - & - & - & - \\
\hline DF & + & + & + & + & + & + & + & + & + & + & + & + & + \\
\hline Raffinose & - & - & - & - & - & - & - & - & - & - & - & - & - \\
\hline Meso & - & - & - & - & - & - & - & - & - & - & - & - & - \\
\hline LA & + & + & + & + & + & + & + & + & + & + & + & + & + \\
\hline
\end{tabular}

DG: D-Glucose; DGal: D-Galactose; Su: sucrose; DM: D-Mannitol; Mal: Maltose; DF: D-Fructose; Meso: Meso-Inositol; LA: L-Arabinose.

coast of Peninsular. These may have been caused by isolation of the same strains of actinomycetes. According to Sujatha and Swethalatha [19] same strains of actinomycetes produce same biochemical characteristics.

Actinomycetes have different main source of carbon [15]. The main determinant of carbon source requirements in actinomycetes is largely but not entirely dependent on the physiological activities of the isolate [2]. This study realized isolates that differed with a previous study with respect to carbon source requirements. The possible reason could be differences in the type of strains isolated and the metabolic pathways utilized by the isolates [7].

\section{Conclusions and Recommendations}

Direct inoculation of soil into the culture medium recovered the highest number of actinomycetes. Menengai crater is a fertile ground of isolating actinomycetes which have varying cultural, morphological, biochemical and carbon source requirements. Some of the actinomycetes could be having antibiotics of medical importance thus there is need to further screen the isolates for antibiotics production.

\section{Conflict of Interest}

There is no conflict of interest. 


\section{References}

1 Adamu AA, Ibrahim N, John O, Matilda AO (2017) Production of novel antifugal compounds from actinomycetes isolated from waste dump soil in western Uganda. European J Biomed Pharm Sci 4: 53-64.

2 Ahmed HG (2017) Phylogenetic Diversity and Anti- MRSA Activity of Halotolerant Actinobacteria from sediments in Great Salt Plains, Oklahoma. Microb Ecol 1: 1-9.

3 Aya N, Shams TK, Tomohiko TM, Kazuo S (2011) Streptomyces aomiensis $s p$. nov, isolated from a soil sample using the membranefilter method. Int J Syst Evol Microbiol 61: 947-950.

4 Bi BZ, Dayanand A, Ambika P (2017) Development of Paper Biosensor for the Detection of Phenol from Industrial Effluents Using Bioconjugate of Tyr-AuNps Mediated by Novel Isolate Streptomyces tuirus DBZ39. J Nanomater 9: 234-240.

5 Ismail S, Ban A, Racha A (2015) Testing of Production of Inhibitory Bioactive Compounds by Soil Streptomycetes as Preliminary Screening Programs in UAE for Anti-Cancer and Anti-Bacterial Drugs. Int J Curr Microbiol Appl Sci 4: 446-459.

6 Jeyaraman T (2015) Isolation, screening and characterization of potent marine Streptomyces sp. pm 105 against antibiotic resistant pathogens. Asian J Pharm Clin Res 8: 439-443.

7 Kadiri SK, Yarla NS, Vidavalur S (2014) Screening and Isolation of Antagonistic Actinobacteria Associated With Marine Sponges from Indian Coast. J Microb Biochem Technol S8: 003.

8 Masna R, Nisha B, Nisha D, Pappu KM (2016) Isolation of antibiotic producing Actinomycetes from soil of Kathmandu valley and assessment of their antimicrobial activities. Int J Allied Sci 2: 22-26.

9 Masoumeh RN, Mehdi FB, Shadi H, Parvin H, Seyyed L (2017) Comparison of Various Methods for Isolation of Nocardia from Soil. Zahedan J Res Med Sci 107: 2-7.

10 Nandhini SU (2015) Gas chromatography-Mass spectrometry analysis of bioactive constituents from the marine Streptomyces. Asian J Pharm Clin Res 8: 244-246.
11 Narendhran S, Rajiv P, Vanathi P, Sivaraj R (2014) Spectroscopic analysis of bioactive compounds from Streptomyces cavouresis kuv39: Evaluation of antioxidant and cytotoxicity activity. Int J Pharm Pharm Sci 6: 319-322.

12 Ravi RK, Vasantba JJ (2016) Isolation of Actinomycetes: A Complete Approach. Int J Curr Microbiol Appl Sc 5: 606-618.

13 Rotich MC, Magiri E, Bii C, Maina N (2017) Bio-Prospecting for Broad Spectrum Antibiotic Producing Actinomycetes Isolated from Virgin Soils in Kericho County, Kenya. Adv Microbiol 7: 56-70.

14 Orooba MF, Ali AS, Khansa MY, Gires U, Asmat A (2017) Isolation, screening and antibiotic profiling of marine Actinomycetes extracts from the coastal of Peninsular Malaysia. Int J ChemTech Res 3: 212-224.

15 Pooja S, Rajesh K, Mahesh SY, Nityanand M, Dilip KA (2015) Isolation and Characterization of Streptomycetes with Plant Growth Promoting Potential from Mangrove Ecosystem. Pol J Microbiol 64: 339-349.

16 Samer MA (2016) Isolation and identification of Actinomycetes with biosurfactant activity. AL-Muthanna J PuR Sci 3: 68-74.

17 Sengupta S, Pramanik A, Ghosh A, Bhattacharyya M (2015) Antimicrobial activities of actinomycetes isolated from unexplored regions of Sundarbans mangrove ecosystem. BMC Microbiol 15: 1.

18 Sinha S, Choubey S, Ajay Kumar A, Bhosale P (2017) Identification, Characterization of Pigment Producing Bacteria from Soil and Water and Testing of Antimicrobial Activity of Bacterial Pigments. Int. J. Pharm. Sci. Rev. Res 42: 119-124.

19 Sujatha P, Swethalatha P (2017) Isolation and screening of novel streptomyces from sediments of bay of bengal near srikakulam coast. Int J Curr Pharm Res 9: 40-44.

20 Vidyasr N, Yamini Sudha LS (2015) Isolation, screening, identification, characterization and application green synthesized silver nanoparticle from marine actinomycetes (Streptomyces Griese Rubens). W J Pharm Res 4: 1801-1820.

21 Yaminisudha LS, Hharithalaksmi D, Sharmila S (2015) Isolation, screening, identification, characterization and application green synthesised silver nanoparticle from marine actinomycetes Streptomyces althioticus. W J Pharm Res 4: 1592-1611. 